overall response rate, suggests rather that, if the sum of responses in any interval is broken down into the 12 15-sec subintervals and expressed for each subinterval as percentages of the total, then the distribution of responses across the subintervals is similar for all Ss.

REFERENCES

CUMMING, w. W \& SCHOENFELD, $\mathbf{w}, \mathbf{N}$ Behavior under extended exposure to a high-value fixed interval reinforcement schedule. Journal of the Experimental Analysis of Behavior, 1958, 1, 245-263. FERSTER, C. B. \& SKINNER, B. F Schedules of reinforcement. New York: Appleton-Century-Crofts, 1957.

FRY, W., KELLEHER, R. T., \& COOK. L. A mathematical index of performance on fixed-interval schedules of reinforcement. Journal of the Experimental Analysis of Behavior, 1960, 3, 193-199.
GOLLUB, $L$, The relations among measures of performance on fixed-interval schedules. Journal of the Experimental Analysis of Behavior, 1964. 7, 337-343.

HERRNSTEIN, R. J., \& MORSE, W. H Effects of pentobarbital on intermittently reinforced behavior. Science, 1957, 125 . 929-931.

SCHNEIDER, B. A. A two-state analysis of fixed-interval responding in the pigeon. Journal of the Experimental Analysis of Behavior, 1969, 12, 677-687.

SKINNER, B. F. The behavior of organisms. New York: Appleton-Century-Crofts, 1938

SNAPPER, A. G., \& KADDEN, R. M. Time-sharing in a small computer through the use of a behavioral notation system. In $B$. Weiss (Ed.) Digital computers in the behavior laboratory. New York: Appleton-Century-Crofts, in press.

SNAPPER, A. G., KNAPP, J. Z., \& KUSHNER, H. K. Mathematical description of schedules of reinforcement. In W. N. Schoenfeld (Ed.), The theory of reinforcement schedules. New York: Appleton-Century-Crofts. 1970. Pp. 247-275.

\section{The effects of prefear conditioning shock intensity on initial shuttle response rate}

\author{
GEORGE A. CICALA and RONALD R. ULM \\ University of Delaware, Newark, Del. 19711
}

The effects of prefear conditioning shock intensity on unreinforced shuttle response rate indicated that unreinforced shuttle response is inversely related to prefear shock intensity. The CS enhanced shuttling equally for all prefear shock groups. The data suggest that prefear conditioning decreases initial shuttle response rate, while the CS partially reverses this effect. An interpretation of demonstrated facilitation by prefear conditioning is offered.

Shuttle avoidance learning has been shown to be inversely related to shock intensity (Moyer \& Korn, 1964; Cicala \& Kremer, 1969) and directly related to intertrial interval (ITI) duration (Murphy \& Miller, 1956; Brush, 1962). A recent experiment (Cicala, Ulm, \& Drews, 1971) demonstrated that these effects emerge in shuttle-avoidance responding in the absence of escape or avoidance contingencies. This finding suggests that shock intensity and ITI duration affect shuttle-avoidance learning by modifying the operant level of the shuttle response, providing differential probabilities of response reinforcement.

Other manipulations may also modify the unreinforced shuttle rate and thereby exert their influence on a voidance learning. For example, prefear conditioning has usually been shown to facilitate the acquisition of shuttle responding (Slotnick, 1968; Baum, 1969), although this facilitation has not always been obtained (Mullin \& Mogenson, 1963; Weiss, Krieckhaus, \& Conte, 1968). Facilitation is usually interpreted in terms of the motivating effects of CS introduction and the reinforcing effects of CS termination in prefear conditioned Ss. Alternatively, it is conceivable that prefear conditioning may increase the initial response rate to the $\mathrm{CS}$ and thereby facilitate avoidance learning. The present experiment was designed to test this hypothesis.

\section{SUBJECTS}

Sixty-three male Wistar rats, 90-110 days old, were used.

\section{APPARATUS}

A test cage constructed entirely of stainless steel grids spaced $1 / 2$ in. apart in a Plexiglas frame, 9 in. long, $7 \frac{1}{2}$ in. wide, and $6^{1 / 2} \mathrm{in}$. high, was used. All of the grids were wired for shock. A speaker directed at the test cage was mounted in the top of a sound-attenuating test cage enclosure. A variable-output, $150-\mathrm{K}$-ohm, fixed-impedance shock source (Campbell \& Masterson, 1969) provided the shock stimuli. Interruptions of a photocell beam bounced across the width of the test cage recorded crossings.

\section{PROCEDURE}

The Ss were divided into eight experimental groups and assigned to a 4 by 2 factorial matrix, varying shock intensity $(45,90,180$, and $360 \mathrm{~V})$ and shock duration $(.5$ and $3 \mathrm{sec})$. During prefear conditioning, each $S$ was placed in the test cage and, after $2 \mathrm{~min}$, was given 10 presentations of a 10-sec 80-dB white-noise CS which terminated with the onset of shock. A control group of seven rats was given $10 \mathrm{CS}$ presentations without shock. The intertrial interval was $20 \mathrm{sec}$ for all groups.

Twenty-four hours after prefear conditioning, Ss were tested by being placed in the test cage and presented with the $10-\sec \mathrm{CS}$ for 10 trials, again separated by a 20-sec ITI. No shock was presented. Crossings, measured by photocell interruptions, served as the index of unreinforced avoidance responding during testing. This measure was taken during the 10 -sec CS period (CS-on) and during the 20-sec ITI betweeen CS presentations. Since the ITI was twice as long as CS-on, activity during ITI was halved (CS-off).

\section{RESULTS AND DISCUSSION}

Mean crossing scores were analyzed by an analysis of variance for factorial experiments using a single control group (Winer, 1962, p. 264). The effects of prefear shock intensity, prefear shock duration, and CS-on vs CS-off were assessed. This analysis showed that prefear shock intensity and presence or absence of CS significantly affected crossing scores $(\mathrm{F}=17.38, \quad \mathrm{df}=4 / 62, \quad \mathrm{p}<.01 ;$ $\mathrm{F}=14.60, \quad \mathrm{df}=1 / 62, \quad \mathrm{p}<.01$; respectively), while prefear shock duration was not significant. None of the interactions was significant.

The main results are presented in Fig. 1, which shows mean crossings during CS-on and during CS-off for 10 CS presentations as a function of prefear shock voltage. Each point is a mean score for all Ss regardless of the prefear shock duration employed. Crossings during CS-on and during CS-off are linearly and inversely related to shock intensity, while crossing rate during CS-on is higher at all shock intensities than during CS-off.

If shuttling in the presence of the CS can be viewed as an index of initial avoidance response rate, the data clearly imply that prefear conditioning under high shock intensity would result in a lower initial avoidance response rate than under low shock intensity or in the absence of shock. However, mean crossing rate during CS-on is not truly analogous to the usual measure of avoidance responding, which is the occurrence of a single crossing on a particular trial. To provide a measure of initial 


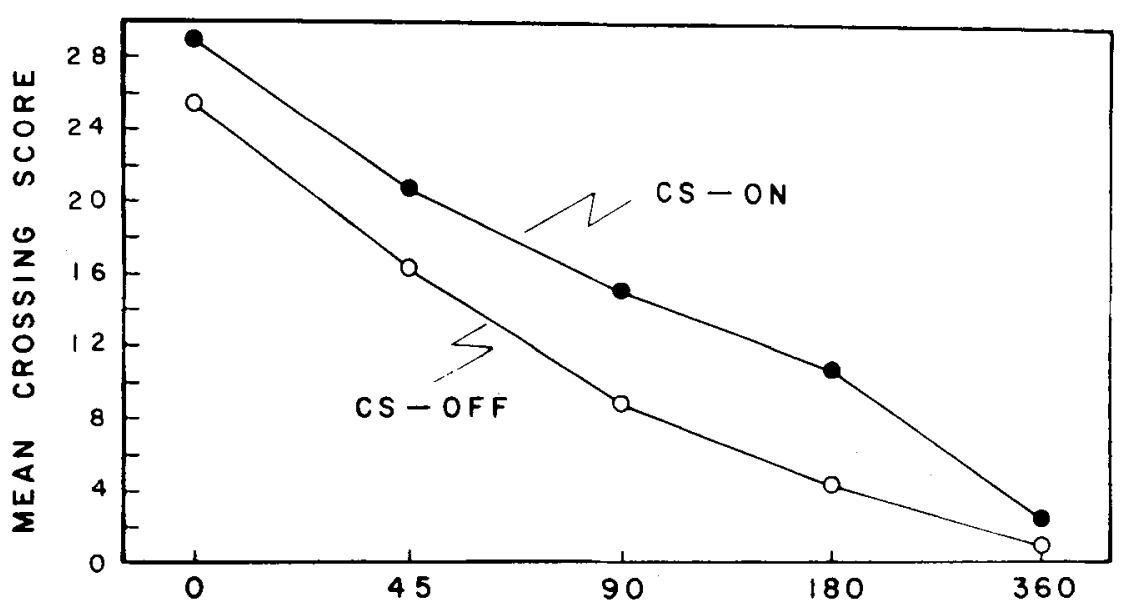

\section{PREFEAR SHOCK VOLTAGE}

Fig. 1. Mean crossing score as a function of prefear conditioning shock intensity. CS-on and CS-off scores are plotted separately.

response rate more analogous to the avoidance response, the number of trials on which each animal crossed at least once during the CS was also obtained and analyzed as a function of shock intensity. A one-way analysis of variance was done using all of the Ss included in the preceding analysis. This measure was inversely related to prefear shock intensity ( $F=3.75$, $\mathrm{df}=4 / 55, \quad \mathrm{p}<.01)$, as was the measure of mean responses during the CS. It appears likely that both of these measures reflect the initial probability of the avoidance response and that this probability is inversely related to prefear shock intensity.

While these results may suggest that the decrement in avoidance learning produced by prefear conditioning in the Weiss et al experiment was due to the reduction in initial response rate, they are inconsistent with the more frequently demonstrated facilitation of avoidance learning by prefear conditioning (Slotnik, 1968; Baum, 1969). It may be that this facilitation was produced by the increased motivational properties of the CS with prefear conditioning, which is only effective when the CS can be response terminated. Thus, the reinforcing effects of CS termination may overcome the detrimental effects of prefear conditioning on initial response rate. The high intensity of prefear shock and the nature of the avoidance situation used by Weiss et al (1968) may have resulted in such infrequent $\mathrm{CS}$ termination that the decreases in initial response rate produced by prefear conditioning were not overcome.

As Fig. 1 clearly shows, the decrease in initial response rate with increases in shock intensity is not specific to the
CS-on period, since CS-off responding also declines with increasing shock intensity. This finding argues strongly against the view that prefear conditioning results in the acquisition of freezing responses specific to the CS (Weiss et al, 1968). Alternatively, it may be that freezing responses are characteristic of CS-off periods, that freezing during CS-off periods increases with shock intensity, and that the introduction of the CS raises response level regardless of the existing CS-off response level. This interpretation is consistent with that of Blanchard \& Blanchard (1969), who showed immobility to be a characteristic response of rats to static situational fear stimuli, while a specific fear CS elicited vigorous activity. In addition, Blanchard \& Blanchard (1968) showed that immobility to situational fear stimuli increased with shock intensity. Further, Cicala, Masterson, \& Kubitsky (in press) have recently shown that a CS which reliably precedes unavoidable inescapable periodic shock occasions greater activity than when no CS is presented.

The present results are strikingly similar to the findings of Cicala, Ulm, \& Drews (1971), who measured crossing rate in an avoidance conditioning situation with intermittent shock presentations and no behaviorally contingent reinforcement. They found that crossing rate decreased as shock intensity increased, that the decrease in rate during CS-on periods paralleled the decrease during CS-off periods, and that the CS-on rate was consistently higher than the CS-off rate. Thus, it is clear that activity enhancement by the CS is found not only when CSs are previously paired with shock, as in the present experiment, but also when the CS and shock are presented during testing.

One important observation was that crossing during CS-on was greater than during CS-off, even when $0 \mathrm{~V}$ of prefear shock was used. This may mean that a CS served a general energizing function regardless of its prior pairing with shock or the intensity of that shock. While this does not deny the fear-eliciting properties of a CS which has been paired with shock, it suggests that the elevation of activity by the CS is not dependent upon its fear-eliciting properties.

\section{REFERENCES}

BAUM, M. Dissociation of respondent and operant processes in avoidance learning. Journal of Comparative \& Physiological Psychology, 1969,67, 83-88.

BLANCHARD, R. J., \& BLANCHARD, C. $D$. Crouching as an index of fear. Journal of Comparative \& Physiological Psychology, 1968, 67, 370-375.

BLANCHARD, R. J., \& BLANCHARD,C. D. Passive and active reactions to fear-eliciting stimuli. Journal of Comparative \& Physiological Psychology, 1969, 68, 129-135.

BRUSH, F. R. The effects of intertrial interval on avoidance learning in rats. Journal of Comparative \& Physiological Psychology, 1962, 55, 888-892.

CAMPBELL, B. A.. \& MASTERSON, F. A. Psychophysics of punishment. In B. A. Campbell and R. M. Church (Eds.), Punishment and aversive conditioning. New York: Appleton-Century-Crofts, 1969.

CICALA, G. A., \& KREMER, E. The effects of shock intensity and d-amphetamine on avoidance learning. Psychonomic Science, 1969, 14, 41-42.

CICALA. G. A., MASTERSON, F. A., \& KUBITSKY, G. L. The role of initial response rate in avoidance learning in rats. Journal of Comparative \& Physiological Psychology, in press.

CICALA, G. A., ULM, R. R., \& DREWS, D. The effects of shock intensity and intertrial interval duration on the operant level of a shuttle avoidance response. Psychonomic Science, 1971, 22, 7-8.

MOYER, K. E., \& KORN. J. H. Effects of UCS intensity on the acquisition and extinction of an avoidance response. Journal of Experimental Psychology, 1964, 67, 353-359.

MULLIN, A. D., \& MOGENSON, G. J. Effects of fear conditioning on avoidance learning. Psychological Reports, 1963, 62, 159-160.

MURPHY, J. V., \& MILLER, R. E. Spaced and massed practice with a methodological consideration of avoidance conditioning. Journal of Experimental Psychology, 1956, 52, 77-81.

SLOTNICK, B. M. Effects of fear conditioning on subsequent acquisition of an avoidance response. Psychonomic Science, $1968,13,159-160$.

WEISS, J. M., KRIECKHAUS, E. E., \& CONTE, R. Effects of fear conditioning on subsequent avoidance behavior and movement. Journal of Comparative \& Physiological Psychology, 1968, 65, 413-431.

WINER, B. J. Statistical principles in experimental design. New York: McGraw-Hill, 1962. 